\title{
Fate and effects of sediment-associated triclosan in subtropical freshwater microcosms
}

Peng, Fengjiao; Diepens, Nöel; Pan, Changgui; Bracewell, Sally; Ying, Guangguo; Salvito, Daniel; Selck, Henriette; van den Brink, Paul

Published in:

Aquatic Toxicology

DOI:

10.1016/j.aquatox.2018.07.008

Publication date:

2018

Document Version

Peer reviewed version

Citation for published version (APA):

Peng, F., Diepens, N., Pan, C., Bracewell, S., Ying, G., Salvito, D., Selck, H., \& van den Brink, P. (2018). Fate and effects of sediment-associated triclosan in subtropical freshwater microcosms. Aquatic Toxicology, 2018(202), 117-225. https://doi.org/10.1016/j.aquatox.2018.07.008

\section{General rights}

Copyright and moral rights for the publications made accessible in the public portal are retained by the authors and/or other copyright owners and it is a condition of accessing publications that users recognise and abide by the legal requirements associated with these rights.

- Users may download and print one copy of any publication from the public portal for the purpose of private study or research.

- You may not further distribute the material or use it for any profit-making activity or commercial gain.

- You may freely distribute the URL identifying the publication in the public portal.

Take down policy

If you believe that this document breaches copyright please contact rucforsk@kb.dk providing details, and we will remove access to the work immediately and investigate your claim. 


\section{Accepted Manuscript}

Title: Fate and effects of sediment-associated triclosan in subtropical freshwater microcosms

Authors: Feng-Jiao Peng, Noël J. Diepens, Chang-Gui Pan, Sally A Bracewell, Guang-Guo Ying, Daniel Salvito, Henriette Selck, Paul J. Van den Brink

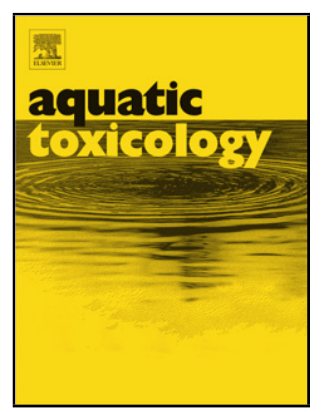

PII: S0166-445X(18)30406-5

DOI:

Reference: https://doi.org/10.1016/j.aquatox.2018.07.008

To appear in: AQTOX 4981

Received date:

Aquatic Toxicology

Revised date:

3-5-2018

Accepted date:

$10-7-2018$

$10-7-2018$

Please cite this article as: Peng F-Jiao, Diepens NJ, Pan C-Gui, A Bracewell S, Ying G-Guo, Salvito D, Selck H, den Brink PJV, Fate and effects of sedimentassociated triclosan in subtropical freshwater microcosms, Aquatic Toxicology (2018), https://doi.org/10.1016/j.aquatox.2018.07.008

This is a PDF file of an unedited manuscript that has been accepted for publication. As a service to our customers we are providing this early version of the manuscript. The manuscript will undergo copyediting, typesetting, and review of the resulting proof before it is published in its final form. Please note that during the production process errors may be discovered which could affect the content, and all legal disclaimers that apply to the journal pertain. 
Fate and effects of sediment-associated triclosan in subtropical freshwater microcosms

Feng-Jiao Peng a, *, Noël J. Diepens ${ }^{\text {a }}$, Chang-Gui Pan ${ }^{\text {b }}$, Sally A Bracewell a, Guang-Guo Ying $^{\text {c }}$, Daniel Salvito ${ }^{\mathrm{d}}$, Henriette Selck ${ }^{\mathrm{e}}$, Paul J. Van den Brink ${ }^{\text {a, f, }}$

${ }^{a}$ Aquatic Ecology and Water Quality Management group, Wageningen University, P.O. Box 47, 6700 AA Wageningen, The Netherlands

${ }^{\mathrm{b}}$ School of Marine Sciences, Guangxi University, Nanning 530004, China

${ }^{\mathrm{c}}$ The Environmental Research Institute, MOE Key Laboratory of Environmental Theoretical Chemistry, South China Normal University, Guangzhou 510006, China

${ }^{\mathrm{d}}$ Research Institute for Fragrance Materials, 50 Tice Boulevard, Woodcliff Lake, NJ 07677, USA

${ }^{\mathrm{e}}$ Department of Science and Environment, Roskilde University, Universitetsvej 1, Denmark

${ }^{\mathrm{f}}$ Wageningen Environmental Research, P.O. Box 47, 6700 AA Wageningen, The Netherlands

* Corresponding author.

Email address: fengjiaopeng@gmail.com

\section{Highlights}

- Benthic macroinvertebrate presence significantly increased the triclosan levels in the overlying water through biological activity.

- Triclosan accumulated in the sediment-dwelling worm.

- Benthic macroinvertebrate presence did not significantly accelerate the triclosan dissipation in the water-sediment systems. 
- Sediment-associated triclosan is unlikely to impose a direct toxicological risk to snail and worm present in the water-sediment systems at environmentally relevant concentrations in the short term.

\section{Abstract}

Triclosan (TCS) is an antibacterial agent that is commonly used in personal care products. Because of its sediment-binding properties, TCS exposure presents a potential threat to sediment-dwelling aquatic organisms. Currently our knowledge of the fate and effects of sediment-associated TCS in aquatic systems is limited. To understand the impact of sedimentassociated TCS, we used microcosms to assess effects of TCS exposure on a diverse range of organisms selected to mimic a subtropical community, with an exposure period of 28 days. We included the oligochaete freshwater worm Limnodrilus hoffmeisteri to evaluate the interaction between sediment-associated TCS and sediment-dwelling organisms, including potential loss of TCS from the sediment due to biological activity and bioaccumulation. Benthic macroinvertebrate presence significantly increased the TCS levels from $0.013 \pm 0.007$ $\mu \mathrm{g} / \mathrm{L}$ to $0.613 \pm 0.030 \mu \mathrm{g} / \mathrm{L}$ in the overlying water through biological activity, posing a potential additional risk to pelagic species, but it did not result in a significant reduction of the sediment concentration. Furthermore, worms accumulated TCS with estimated BiotaSediment-Accumulation-Factors (BSAFs) ranging between 0.38-3.55. Other than for algae, TCS at environmental concentrations did not affect the survival of the introduced organisms, including the L. hoffmeisteri. Our results demonstrate that, although TCS at currently detected maximum concentration may not have observable toxic effects on the benthic macroinvertebrates in the short term, it can lead to bioaccumulation in worms.

Keywords Benthic macroinvertebrates; Partitioning; Dissipation; Bioaccumulation; Toxicity 


\section{Introduction}

Chemicals used in personal care products are frequently discharged into the aquatic environment, due to high consumer use throughout the world, and have a range of environmental impacts (Bedoux et al., 2012). Some substances used in personal care products are environmentally persistent and can bioaccumulate in the tissues of aquatic organisms (Brausch and Rand, 2011; Liu and Wong., 2013). Triclosan (TCS; 5-chloro-(2,4dichlorophenoxy) phenol) is a synthetic and broad-spectrum antibacterial agent that is widely used in personal care products, textiles, plastics, and food contact materials (SCCS 2010). In the aquatic environment, TCS is one of the most commonly detected organic contaminants (Halden and Paull, 2005; Brausch and Rand, 2011) with concentrations of $1.02 \mu \mathrm{g} / \mathrm{L}$ detected in some regions (Bedoux et al., 2012). TCS exposure can affect a variety of aquatic organisms (e.g., Orvos et al., 2002; Yang et al., 2008; Khatikarn et al., 2016; Zhang et al., 2016), with algae being particularly sensitive at environmentally relevant concentrations $\left(\mathrm{EC}_{50}\right.$ of 0.7 $\mu \mathrm{g} / \mathrm{L})$ (Orvos et al., 2002). Currently, our knowledge of the toxic effects of TCS exposure is mainly derived from laboratory-based single-species studies. However, because of the hydrophobic property of TCS (Reiss et al., 2002), it is likely that sediment-dwelling aquatic organisms may be affected by TCS exposure (Dussault et al., 2008; Tamura et al., 2013). Nevertheless, there is limited knowledge of the effects of TCS on sediment-dwellers and the interaction between sediment-bound TCS and the water phase in a multi-species community.

TCS can sorb to particles in the water column as well as accumulate in the sediment due to its high hydrophobicity ( $\log K_{o w}$ of $4.8, \log K_{o c} 3.11$ to 4.48) (Reiss et al., 2002). In the water phase, TCS can readily degrade under controlled laboratory conditions via various mechanisms (e.g. photolysis, chlorination, ozonolysis, and sonochemical treatment) and has 
short half-lives in the range of less than 3 milliseconds - around 1 day (Bedous et al., 2012). In soil and sediment, however, TCS is more resistant to biodegradation with reported halflives of up to 239 days (Ying et al., 2007; Wu et al., 2009; Huang et al., 2015). TCS is frequently identified in the sediments of water bodies (e.g., Cantwell et al., 2010; Katz et al., 2013; Gorga et al., 2015), with the highest reported level of $1.33 \mu \mathrm{g}$ TCS/g dry weight (dw) sediment (Zhao et al., 2010). However, there are no sediment quality guidelines. In addition, although there are single-species toxicity data for TCS and invertebrates such as the freshwater amphipod Hyalella azteca and the midge Chironomus sp (Dussault et al., 2008; Tamura et al., 2013), no studies examining the effects of sediment-associated TCS on benthic macroinvertebrates under more ecologically realistic conditions have been performed. This limits the prediction of the TCS effect of maximum environmental concentrations on aquatic organisms, especially benthic species.

In addition to a sink of hydrophobic contaminants, sediments can serve as a source of contaminants when sediment is re-suspended during physical disturbance or biological activity (Burton, 2002). Through their feeding habits and bioturbation behaviour (e.g., sediment irrigation and particle mixing), sediment-dwelling benthic macroinvertebrates, such as oligochaete worms, can alter the physicochemical properties of sediment and sequentially the fate and effects of sediment-bound contaminants. For example, bioturbation can provide elevated oxygenation that can promote microbial degradation processes (Banta and Andersen, 2003; Eggleton and Thomas, 2004). Bioturbation may also increase the transfer of contaminants from the sediment to the overlying water (Eggleton and Thomas, 2004). For example, bioturbation by benthic macroinvertebrates, such as polychaetes and oligochaetes, enhanced the transport of hydrophobic organic contaminants from sediment to the water phase (Thibodeaux et al., 2001; Josefsson et al., 2010). Thus, bioturbation may influence the 
fate of sediment-bound contaminants (Schaffner et al., 1997) and potentially increase contaminant-associated risks to pelagic species (Pang et al., 2012). Besides, sedimentdwellers may be able to accumulate sediment-associated contaminants from their environment via different routes, such as pore water, overlying water and ingestion of sediment (Selck and Forbes, 2004). For example, TCS can accumulate in the freshwater sediment-dwelling worm Lumbriculus variegatus with a 28-d Biota-Sediment-Accumulation-Factor (BSAF) of 1.4 (Dang et al., 2016). Therefore, bioaccumulation might be an important pathway for hydrophobic organic contaminants like TCS. Despite this interaction between sediment-bound contaminants and benthic macroinvertebrates, the influence of these organisms on sedimentassociated TCS has not been well explored.

We explored the fate and effects of TCS in an environmentally realistic manner using a microcosm setup. The microcosms were comprised of TCS contaminated sediment and representative aquatic communities mimicking a subtropical freshwater ecosystem. We examined subtropical conditions because the currently detected maximum (1.33 $\mu \mathrm{g}$ TCS/g $\mathrm{dw}$ ) occurred in a subtropical river (Pearl River, South China). Also, since TCS has been phased out or banned in the USA and Europe (ECHA, 2015; FDA, 2016), the subtropical environment is most likely to be exposed to the highest levels which has been confirmed by measurements reported by Peng et al. (2017). To investigate the effects of benthic macroinvertebrates for the fate of TCS in the microcosms, we included a sediment-dwelling worm, Limnodrilus hoffmeisteri, from the Naididae family. The Naididae family (formerly known as Tubificidae) are highly abundant in contaminated sediments due to their tolerance to a range of contaminants (Vivien et al., 2015). As such, Naididae are commonly used to assess the quality of aquatic ecosystems in field and laboratory studies, such as in ecotoxicological tests and bioaccumulation studies (Milbrink, 1973; Rodriguez and 
Reynoldson, 2011). To create a more realistic system, we also included pelagic species: algae and Daphnia. As a result, the benthic-pelagic interaction can be examined. Specifically, we aimed to (i) determine the impact of L. hoffmeisteri for the fate of sediment-associated TCS in the microcosm, and (ii) get a better understanding of the direct and indirect toxic effects of sediment-associated TCS on the biological community of a subtropical aquatic environment. To do this, we quantified the fate of sediment-associated TCS in indoor benthic microcosms with and without the presence of introduced organisms, and examined the effects of sedimentassociated TCS on algae, Daphnia, snails, midges and sediment-dwelling worms.

\section{Material and methods}

\subsection{Chemicals}

The TCS standard was obtained from J\&K Scientific Ltd (Beijing, China) with a purity of 97\%, and ${ }^{13} \mathrm{C}_{12}$-triclosan was purchased from Cambridge Isotope Laboratories (Andover, USA). The HPLC grade reagents including methanol, acetonitrile, ethyl acetate, hexane, dichloromethane, formic acid and acetic acid were supplied by Merck (Germany), CNW Technologies (China), and Tedia (USA). Glass fiber filters (GF/F, pore size $0.7 \mu \mathrm{m})$ were obtained from Whatman (Maidstone, UK). Oasis HLB cartridges (200 mg, $6 \mathrm{~mL}$ ) were from Waters (Milford, USA). HPLC-grade water was from a Milli-Q water purification system (Millipore, Watford).

\subsection{Test organisms}

Following extensive biomonitoring in six urban rivers of Guangzhou City, South China in 2015, several key common species were identified and selected as representative species. To create a representative subtropical community, we used: five species of algae (Chlorella pyrenoidosa, Scenedesmus obliquus, Selenastrum capricornutum, Scenedesmus acuminatus, 
and Chlamydomonas reinhardtii); a filter-feeding cladoceran (Daphnia magna); a filterfeeding detritivorous snail (Viviparidae bellamya); an insect midge larvae (Orthocladiinae) at fourth instar stage; and a sediment-dwelling worm (Limnodrilus hoffmeisteri).

The algae were laboratory cultured in BG11 medium at $25^{\circ} \mathrm{C}$ and a light intensity of 4000 lux with a dark/light cycle of $14 \mathrm{~h} / 10 \mathrm{~h}$. The preparation of BG11 medium can be found in a previous study (Rippka et al., 1979). D. magna was laboratory reared in an incubator at $20{ }^{\circ} \mathrm{C}$ under a cool white fluorescent lamp on a photoperiod of $16 \mathrm{~h}$ light: $8 \mathrm{~h}$ dark. D. magna was fed with yeast and the algae Chlorella pyrenoidosa. Snails, midge larvae, and juvenile worms were purchased from an aquatic market (Guangzhou, South China), as they could not be collected in the field, and placed into separate 18-L glass holding tanks with aerated tap water and unbleached tissue paper as substrate. Snails and worms with similar size and mass (representing similar age) were selected and cultured for 2 weeks in the laboratory at the same light and temperature conditions as the microcosm experiment (light/dark: 12/12 h, temperature: $27 \pm 1^{\circ} \mathrm{C}$ ). Midge larvae were only cultured for 2 days as they were near emergent stage. During the culturing period ( 2 weeks), snails were fed with lettuce in small slices every day, while worms were fed with ground fish food (Tetramin; Tetra Werke) twice a week. The culturing systems for snails, midge larvae and worms were cleaned every day by taking out all animals and washing the glass tanks with aerated tap water.

One day before being added to the microcosms, midges, worms and snails were transferred to glass beakers separately and allowed to clear their guts by defecating in aerated tap water overnight (Dai et al., 2012). In this study, the endpoint was based on survival and reproduction for D. magna, and on growth inhibition assessed as changes in wet weight, survival and reproduction for midges, worms, and snails. The wet weights (ww, mg) of 
midges, worms, and snails were estimated by measuring 50 randomly selected individuals at the start of the experiment (Sartorius balance, Germany) (see Table S1 for all body lengths and wet weights). The species traits are also provided in Table S1. Midges, worms, and snails are all benthic macroinvertebrates, but they show different traits. For example, midges have a shorter life cycle duration ( $\leq 1$ year) than worms and snails ( $>1$ year) (Usseglio-Polatera et al., 2000). Also, snails show a different reproduction strategy (e.g., ovoviviparity versus clutches, cemented or fixed) and feeding habitat (e.g., shredder, scraper and filter feeder versus deposit feeder) compared to midges and worms (Tachet et al., 2000; Usseglio-Polatera et al., 1999; 2000).

\subsection{Test sediment and TCS spiking}

Sediment was collected in September 2015 from an uncontaminated site (Liuxi Reservoir, Guangzhou, South China) (Zhao et al., 2010; Peng et al., 2017). The sediment was wet sieved through a $300 \mu \mathrm{m}$ sieve using deionized water to remove potential benthic macroinvertebrates. No organisms were observed in the collected sediment, probably due to the depth of the water column (40-50 meters) in the reservoir. After settling for a week, the overlying water was removed, and the wet sediment was first well mixed using a stainless steel mixer, followed by a manual mixture using a metal spade to achieve sediment homogenization. The sieved sediment contained $62 \%$ water. The sediment was composed primarily of clay (56\%), but also silt (43\%), and sand (0.65\%). It contained $1.9 \%$ organic matter $(\mathrm{OM}), 0.04 \%$ total phosphorus, $0.16 \%$ total nitrogen, and $0.01 \%$ ammonia nitrogen $\left(\mathrm{NH}_{3}\right)$ quantified using standard methods (Clesceri et al., 1998). The TCS concentration was found to be less than $0.002 \mu \mathrm{g} / \mathrm{g} \mathrm{dw}$ in the sediment and considered negligible for the purposes of this study. 
The sediment was spiked with TCS dissolved in acetone to reach actual TCS concentrations of 0.8 (treatment 1, T1, $2.76 \mathrm{nmol} / \mathrm{g} \mathrm{dw}$ ), 8 (treatment 2, T2, $27.6 \mathrm{nmol} / \mathrm{g} \mathrm{dw}$ ), 80 (treatment 3, T3, $276 \mathrm{nmol} / \mathrm{g} \mathrm{dw}$ ) and $240 \mu \mathrm{g} / \mathrm{g} \mathrm{dw}$ (treatment 4, T4, $829 \mathrm{nmol} / \mathrm{g} \mathrm{dw}$ ). The same volume of acetone $(6.45 \mathrm{~mL})$ was added to all treatments. Both solvent control and water control were included by replacing TCS stock solution with the same volume of acetone and aerated MilliQ water, respectively. The lowest TCS concentration used here is at environmentally relevant levels $(1.33 \mu \mathrm{g} / \mathrm{g} \mathrm{dw}$, Zhao et al., 2010). However, other TCS levels were used to evaluate the effects of sediment-associated TCS on the test organisms. After spiking, the sediment was thoroughly mixed for $30 \mathrm{~min}$ in a stainless steel mixer. Further pre-equilibration was performed by manually mixing the spiked sediment for 5 minutes using a spade during the following four days. Before introduction to the microcosms, each spiked sediment was further mixed for 20 min using the stainless steel mixer.

\subsection{Microcosm set-up}

We used 52 indoor glass microcosms $(30 \times 30 \times 20 \mathrm{~cm})$ in a temperature-controlled room $(27$ $\pm 1{ }^{\circ} \mathrm{C}$ ), to mimic static subtropical aquatic sediment systems. For each TCS treatment level (T1, T2, T3 and T4), 9 microcosms were filled with $4 \mathrm{~cm}$ of corresponding TCS spiked sediment $(3.6 \mathrm{~L})$ and $14 \mathrm{~cm}$ of aerated tap water $(12.6 \mathrm{~L} ; 0.056 \%$ total organic carbon (TOC), $0.001 \%$ total phosphorus, $0.164 \%$ nitrate $\left(\mathrm{NO}_{3}{ }^{-}\right), 0.0002 \%$ nitrite $\left(\mathrm{NO}_{2}^{-}\right)$and $\left.0.030 \% \mathrm{NH}_{3}\right)$. Eight microcosms each were used for water and acetone controls. After introduction of spiked sediment and aerated tap water, the particles in the water phase were allowed to settle for 3 days before addition of the test organisms. Before introducing organisms into microcosms, 1 replicate of the 9 microcosms assigned to each treatment was sacrificed to measure TCS concentrations in the overlying water and sediment phase for each TCS treatment. at the start of the exposure (day 0). Therefore, there were 8 microcosms for controls and each treatment 
level (see Fig. S1): 4 with sediment and water only (i.e., without test organisms) and 4 with sediment, water, and test organisms (40 midges, 240 worms, 6 snails, 30 D. magna, and algae at a density of approximately $10^{4}$ cells/mL per microcosm). Test organisms were added on day 0 and the experiment ran for 28 days. Because periphyton can develop in the microcosms during the experiment, the effect of sediment-associated TCS on periphyton community development was investigated by introducing five microscopic glass slides $(7.5 \times 2.5 \mathrm{~cm})$ into each microcosm at a water depth of about $10 \mathrm{~cm}$.

Microcosms were illuminated with a cool white fluorescent light (2200 lux) and a daily photoperiod of $12 \mathrm{~h}$. Each microcosm was aerated using a glass pipette connected to an aeration system. During the experiment, evaporated water was replenished with aerated tap water weekly to maintain the original water level. Nitrogen $(0.7 \mathrm{mg} / \mathrm{L}$ as urea $)$ and phosphorus $(0.09 \mathrm{mg} / \mathrm{L}$ as triple super phosphate) were added biweekly to the systems to provide nutrients for algal growth (Rico et al., 2014).

To determine the effects of abiotic degradation (i.e., photolysis and hydrolysis) of TCS during the exposure, we performed two parallel fate experiments using similar conditions as the microcosm experiment (see Text S1 for test details). Briefly, we performed the first experiment using six 1-L Erlenmeyer flasks with $500 \mathrm{~mL}$ de-chlorinated tap water containing $2 \mathrm{mg} / \mathrm{L} \mathrm{TCS}$, to mimic abiotic degradation in low turbidity water (the worst scenario). For the other experiment, we used six 500-mL Erlenmeyer flasks containing $250 \mathrm{~mL}$ of overlying water collected from T1, to mimic abiotic degradation in high turbidity water. In each experiment, we divided Erlenmeyer flasks into 2 group: with and without covering in aluminium foil. Flasks with aluminium foil were used to determine TCS hydrolysis whereas 
those without were used to measure TCS photolysis by comparison with those with aluminium foil.

\subsection{Sampling, water and sediment quality parameter analysis}

Dissolved oxygen (DO: mg/L), temperature $\left({ }^{\circ} \mathrm{C}\right), \mathrm{pH}$ and conductivity $(\mu \mathrm{S} / \mathrm{cm})$ of the microcosms were monitored in the afternoon $(15: 00 \mathrm{hrs})$ on days $-1,1,2,4,7,11,14,18,21$ and 28 using a multi-meter placed at a water depth of $7 \mathrm{~cm}$. Turbidity (NTU) was measured (15:00 hrs) using a turbidimeter on days $0,1,7,14,21$ and 28.

At the end of the experiment (day 28), two water samples $(0.5 \mathrm{~L})$ were taken using a Teflon siphon from each microcosm. One sample was used to determine TCS concentration, while the other was used to determine water parameters including $\mathrm{NH}_{3}, \mathrm{NO}_{3}{ }^{-}, \mathrm{NO}_{2}{ }^{-}$, total phosphorus and TOC. To measure TCS concentration and sediment quality parameters including total nitrogen, $\mathrm{NH}_{3}$, total phosphorus and $\mathrm{OM}$, a sediment column (depth $4 \mathrm{~cm}$, diameter $3 \mathrm{~cm}$ ) was collected from each microcosm using a thin-walled metal corer (inner diameter $3 \mathrm{~cm}$, height $8 \mathrm{~cm})$. Sediment samples were amended with sodium azide $(1 \mathrm{~g} / \mathrm{L})$ to suppress any potential microbial activity, frozen at $-20^{\circ} \mathrm{C}$, freeze-dried, homogenized, and passed through a $0.83 \mathrm{~mm}$ mesh. The sediment was stored at $4{ }^{\circ} \mathrm{C}$ until extraction.

\subsection{TCS analysis}

TCS concentrations in the overlying water were determined at the start (day 0) and end (day 28) of the experiment. TCS concentrations in the sediment and worms were assessed prior to addition to the microcosms and on day 28. Additionally, TCS concentrations were also determined in the initial aerated tap water that was added to the microcosms. TCS in water samples was extracted using solid-phase extraction (SPE), while TCS in sediment samples 
was extracted by ultrasonic extraction combined with SPE purification (Chen et al., 2012).

TCS in worm tissue was extracted by QuEChERS (quick, easy, cheap, effective, rugged, and safe) extraction combined with dispersive solid-phase extraction (d-SPE) clean-up method (Yao et al., 2016). Detailed extraction methods are given in the supporting information (Text S2). TCS in extracts were analysed by high performance liquid chromatography-tandem mass spectrometry (HPLC-MS/MS) with electrospray ionization (ESI) in the negative mode according to Chen et al. (2010) (Text S3).

\subsection{Organism sampling and analysis}

At the end of the experiment, algae, D. magna, midges, worms and snails were sampled from the 24 microcosms where they had been introduced. To assess the algal biomass in the water phase of these 24 microcosms, the chlorophyll-a content was measured by removing a $1 \mathrm{~L}$ water sample from each microcosm and filtering it through a Whatman GF/C glass-fibre filter (mesh size: $0.45 \mu \mathrm{m}$ ). Chlorophyll-a samples were extracted following the methods outlined in Zhou et al. (2012). The chlorophyll-a extracts were analysed spectrophotometrically following the methods of Li et al. (2000). Using a Teflon siphon, a further $10 \mathrm{~L}$ of water was collected from each microcosm and passed through a plankton net (mesh size: $55 \mu \mathrm{m}$ ) to sample D. magna abundance. Lugol's iodine solution was added to the sieved samples to fixate any organisms and samples were stored at $4{ }^{\circ} \mathrm{C}$ until further analysis. D. magna individuals were counted using a binocular microscope at a magnification of 15-25x. Microscopic glass slides were also retrieved and the attached periphyton was collected by scraping them (in $0.5 \mathrm{~L}$ of de-chlorinated tap water) until the slides were visually clean (Rico et al., 2014). The chlorophyll-a in the water containing the scraped periphyton was then measured as mentioned above. The periphyton content was obtained by dividing the total chlorophyll-a mass in the above water sample by the area of the glass slide that was scraped. 
After removing the water phase, the sediment was gently sieved using a $300 \mu \mathrm{m}$ mesh, the same mesh size used to sieve the sediment before the construction of the microcosms, to collect midges, worms and snails. The collected benthic macroinvertebrates were then placed overnight into bottles with aerated tap water to empty their guts and remove any adhering TCS. The wet weight of each snail was measured after 28 -d exposure and preserved in $70 \%$ ethanol. The wet weight of worms was estimated by randomly taking out a sub-sample of 20 worms from each microcosm with introduced organisms, worms were then released back to the container where they purged. Subsequently, worms were frozen at $-20{ }^{\circ} \mathrm{C}$ until further TCS analysis. However, there were no midges in any of the system at the end of the experiment.

\subsection{Data analysis}

TCS dissipation in the microcosms after 28 days exposure was examined using mass balance calculation, i.e. spiked TCS mass minus TCS mass in overlying water and sediment at the end of experiment. To assess body burden of TCS in the worms tissue, Biota-SedimentAccumulation-Factor (BSAF) was calculated at the end of the exposure (day 28) using the following formula (Ankley et al., 1992): $\left(\mathrm{C}_{\text {org,ww }} / f_{\text {lip }}\right) /\left(\mathrm{C}_{\text {sed,Dw }} / f_{\text {oM }}\right)$, where $\mathrm{C}_{\text {org }}$ is the chemical concentration in the organism ( $\mu \mathrm{g} / \mathrm{g}$ wet weight (ww)), $\mathrm{C}_{\text {sed }}$ is the chemical concentration in sediment $(\mu \mathrm{g} / \mathrm{g} \mathrm{dw}), f_{\text {lip }}$ is the lipid percentage of the organism (ww) and $f_{\mathrm{OM}}$ is the percentage of organic matter $(\mathrm{dw})$. To explain differences between measured BSAF values among treatments, identify the most significant uptake pathways and check if a steady state at the end of the experiment was reached, we used the bioaccumulation model proposed by Diepens et al. (2015) (see Text S4 for model parameterization). The model equation is: 
$B S A F_{t}=\frac{C_{L, t=0}}{C_{O M, t=0}^{S E D}} \times e^{-\left(k_{e}+k_{g}\right) t}+\frac{k_{e} K_{l i p} / K_{O M}^{S E D}+\alpha I[\beta+(1-\beta) \gamma]}{\left(k_{e}+k_{g}\right)} \times\left(1-e^{-\left(k_{e}+k_{g}\right) t}\right)$

where $C_{L, t=0}$ is the measured background concentration in the macroinvertebrate lipid at time zero, $C_{O M, t=0}^{S E D}$ the measured concentration in the sediment at time zero, normalized to organic matter content, $k_{e}\left(\mathrm{~d}^{-1}\right)$ the rate constant for overall elimination, $k_{g}\left(\mathrm{~d}^{-1}\right)$ the growth dilution, $\mathrm{t}$ (d) the exposure time, $K_{\text {lip }}$ the lipid/water partition coefficient, $K_{O M}^{S E D}$ the sediment OM-water partition coefficient, $\alpha(-)$ the chemical assimilation efficiency, and I $\left(\geq 0, k_{g O M} \times k_{g L I P}^{-1} \times\right.$ $\left.d^{-1}\right)$ the mass of OM ingested per unit of time and organism lipid weight, $\beta(0<\beta<1)$ the fraction of ingested OM originating from the sediment, $\gamma$ the constant ratio to estimate the relation between $K_{O M}^{S S}$ (suspended solid OM-water partition coefficient) and $K_{O M}^{S E D}$. In the model, we assumed that L. hoffmeisteri, as a bulk feeder, feed only sediment (SED) $(\beta=1)$, which includes sediment particles and recently settled particles from the water column, corresponding to earlier model results for a similar freshwater worm Lumbricules variegatus (Sidney et al., 2016). The percentage uptake through water is calculated based on equation as:

$\%$ WaterUptake $=\frac{k_{e}}{k_{e}+\alpha I[\beta+(1-\beta) \gamma] K_{O M}^{S E D} / K_{\text {lip }}}$

The fraction of steady state reached $\left(F_{S S}, 0<F_{S S}<1\right)$ in the 28-days bioaccumulation test $(\mathrm{t}=$ 28 d) was calculated as:

$F_{S S}=1-e^{-\left(k_{e}+k_{g}\right) t}$

No observed effect concentrations (NOECs) were calculated for water parameters, sediment parameters, phytoplankton chlorophyll a, periphyton chlorophyll a and survival of benthic macroinvertebrates using the Williams test (Williamss, 1972) which assumes a concentrationeffect relationship and is, therefore, used extensively for the analysis of the results of eco- 
toxicity tests. The Williams tests were performed using the Community Analysis computer program, version 4.3.05 (Hommen et al., 1994). In order to down-weigh high abundance values and obtain approximately a normal distribution of the data, the abundance values of species were $\ln (\mathrm{Ax}+1)$ transformed, where $\mathrm{x}$ represents the abundance data and A was the value through dividing 2 by the lowest abundance value higher than zero for $\mathrm{x}$ (Van den Brink et al., 2000; Rico et al., 2014).

Differences in water parameters, sediment parameters, TCS concentrations, loss of TCS in the microcosms, phytoplankton chlorophyll-a, and periphyton chlorophyll-a concentrations were examined between microcosms with and without macroinvertebrates, using SPSS version 23.0. Prior to analyses, data were examined for normality using Shapiro-Wilk test, and homogeneity of variance between systems was detected by Levene's test. Accordingly, a twoway analysis of variance (ANOVA), one-way ANOVA, Kruskal-Wallis test, two independent samples t-test, Mann-Whitney test or Wilcoxon matched-pairs test was conducted. When significant ANOVA main effect was detected, Tukey's test was used for post hoc comparisons. A significance level of $p=0.05$ was set for comparison between means or ranksum values.

\section{Results}

\subsection{Water and sediment quality parameters}

Dissolved oxygen concentration and temperature remained between 6-7 $\mathrm{mg} / \mathrm{L}$ and $25-26{ }^{\circ} \mathrm{C}$ in the microcosms during the exposure period, respectively. During the first week of exposure $\mathrm{pH}$ was stable between 7.2-7.5 in all of the microcosms (Table S2). By the end of the experiment, a slight drop in $\mathrm{pH}$ was measured (from $7.45 \pm 0.05$ to $6.29 \pm 0.11$ ) in all microcosms. While conductivity values in most of the microcosms remained around 120-150 
$\mu \mathrm{S} / \mathrm{cm}$, conductivity was higher in $\mathrm{T} 4$ in the microcosms containing organisms than those from all the remaining treatments and controls (140-180 $\mu \mathrm{S} / \mathrm{cm})$ (Table S3). Turbidity decreased from day $0(\sim 200 \mathrm{NTU})$ to day $28(<15 \mathrm{NTU})$ in all microcosms with and without introduced organisms (Table S4).

In comparison to the initial added aerated tap water, $\mathrm{NO}_{2}{ }^{-}$and total phosphorus in the water phase remained at similar low levels after 28 days exposure in controls and all treatments, whereas the TOC concentration increased approximately 6-fold to 9-fold after 28 days exposure in controls and all treatments (Wilcoxon matched-pairs test, $p<0.05$ ) (Table S5). In the microcosms containing the introduced organisms, T4 showed significantly higher levels of $\mathrm{NH}_{3}, \mathrm{NO}_{2}{ }^{-}$and TOC than controls; $\mathrm{NO}_{3}{ }^{-}$concentration was significantly higher in all TCS treatments than controls (Williams test, $p<0.05$ ) (Table S5). In the microcosms without introduced organisms, $\mathrm{T} 4$ showed significantly higher levels of $\mathrm{NO}_{2}{ }^{-}$and TOC than controls; $\mathrm{NO}_{3}{ }^{-}$concentration was significantly higher in T2, T3 and T4 than controls (Williams test, $p<$ 0.05) (Table S5). There was no significant difference in total phosphorous (two independent samples t-test), $\mathrm{NO}_{2}^{-}$(two independent samples t-test) and TOC (Mann-Whitney test) between systems with and without introduced organisms. $\mathrm{NH}_{3}$ and $\mathrm{NO}_{3}{ }^{-}$concentrations were significantly higher in the system with introduced organisms than without (Mann-Whitney test, $p<0.05)$.

By the end of the experiment, the total nitrogen and $\mathrm{NH}_{3}$ concentration in the sediment were significantly lower in both systems compared to those in the original sediment (Wilcoxon matched-pairs test, $p<0.05)$. OM and total phosphorous concentrations did not change significantly over time in any of the microcosms (Wilcoxon matched-pairs test) (Table S6). In the microcosms containing the introduced organisms, T4 showed significantly higher level of 
$\mathrm{NH}_{3}$ than the controls (Williams test, $p<0.05$ ). In the microcosms without introduced organisms, T3 and T4 showed significantly higher levels of $\mathrm{NH}_{3}$ than the controls (Williams test, $p<0.05)$. There was no significant difference in $\mathrm{OM}$, total nitrogen, total phosphorous and $\mathrm{NH}_{3}$ between systems with and without introduced organisms (two independent samples t-test).

\subsection{TCS concentrations in water, sediment and worms}

The TCS concentrations in the overlying water, sediment and worms were analysed at the start and end of exposure (day 0,28) (Table 1). The concentrations of TCS in both the water and sediment phase of the control groups were negligible $(<0.002 \mu \mathrm{g} / \mathrm{L}$ or $0.002 \mu \mathrm{g} / \mathrm{g} \mathrm{dw})$ at both time points. After 28 days exposure, TCS concentrations decreased (> 90\%) significantly in the overlying water both in systems with and without introduced organisms (Wilcoxon matched-pairs test, $p<0.05$ ) (Table 1). In the microcosms containing introduced organisms, TCS concentration was significantly higher at T2 and T3 than T1 and T4 (one-way ANOVA, $p<0.05)$, with the highest level $(0.613 \pm 0.030 \mu \mathrm{g} / \mathrm{L})$ measured at T2 (Table 1$)$. In the microcosms without introduced organisms, TCS concentration was significantly higher ( 38fold) at T4 than T1 (Kruskal-Wallis test, $p<0.05$ ). There was a significant difference in TCS concentration in the overlying water between systems with and without introduced organisms (Mann-Whitney test, $p<0.05$ ), such that the overlying water concentration was $\sim 1.1$-fold to 56-fold higher in systems with than without organisms.

By the end of experiment, in both systems TCS concentrations in the sediment were significantly lower than the initial spiked TCS concentrations by $3.43 \% \pm 0.56 \%$ $11.76 \% \pm 0.64 \%$ in system with introduced organisms and $3.46 \% \pm 0.43 \%-10.91 \% \pm 0.50 \%$ in system without introduced organisms (Wilcoxon matched-pairs test, $p<0.05$ ) (Table 1). 
There was no significant difference in TCS concentration in the sediment between systems with and without introduced organisms at experimental end (Mann-Whitney test).

There was a significant TCS dissipation in both systems relative to the initial spiked TCS amount (Wilcoxon matched-pairs test, $p<0.05$ ) (Table S7 and Fig. 1). In microcosms containing the introduced organisms, the decreased TCS amount in the microcosms of T1 $(11.4 \% \pm 0.63 \%)$ was significantly higher than that of $\mathrm{T} 4(3.43 \% \pm 0.56 \%)$ (Kruskal-Wallis test, $p<0.05$ ) (Table S7 and Fig. 1). In the microcosms without introduced organisms, the decreased TCS amount in the microcosms of T1 $(10.9 \pm 0.50 \%)$ was significantly higher than that of T4 $(3.46 \pm 0.43 \%)$ (Kruskal-Wallis test, $p<0.05)$. Although TCS dissipation in the sediment was greater $(0.12-0.50 \%$ in different treatments $)$ in the microcosms with introduced organisms compared to those without, there was no significant difference in decreased TCS amount between systems with and without introduced organisms (Mann-Whitney test).

In the synchronized photolysis and hydrolysis experiments that were used to determine the abiotic degradation of TCS, under light conditions, TCS remained at the initial spiked concentration of $2 \mathrm{mg} / \mathrm{L}$ in the aerated tap water until day 14 and decreased to approximately $1 \mathrm{mg} / \mathrm{L}$ by day 28 (Text S1; Table S8). In contrast, under the dark conditions, TCS remained at around $2 \mathrm{mg} / \mathrm{L}$ in the aerated tap water throughout the 28 days. In the water collected from the sacrificed microcosms of T1, there was no significant difference in TCS concentration between light conditions $(5.24 \pm 0.56 \mu \mathrm{g} / \mathrm{L})$ and dark conditions $(5.27 \pm 0.34 \mu \mathrm{g} / \mathrm{L})$ on day 28 (Text S1; Table S8).

At experimental end, TCS was detected in the worm, with concentrations of 154, 552, 1650 $\mu \mathrm{g} / \mathrm{g}$ tissue lipid weight (lw) in T1, T2 and T3, respectively (Table 1). Since all worms died in 
T4 (see section 3.3 below), no measurement was performed here. The TCS concentration was significantly higher in T3 than T1 (Kruskal-Wallis test, $p<0.05$ ). Although the tissue concentration increases with increasing chemical concentration, the rate of increase decreases. Thus, the tissue concentrations are relatively higher in $\mathrm{T} 2$ compared to $\mathrm{T} 1$ (3.6x increase) and in $\mathrm{T} 3$ compared to $\mathrm{T} 2$ (3x increase) while the increase in sediment concentration stays equal among treatments (i.e., 10x increase). To gain a 10x increase in tissue concentration, the sediment concentration needs to increase 100x (from T1 to T3). Correspondingly, BSAF values decreased with increasing exposure concentration, decreasing from $3.55( \pm 0.16)$ in $\mathrm{T} 1$ to $0.38( \pm 0.01)$ in T3 (Table 1). The bioaccumulation model was used as an aid to further explain this observation. The model provided a good fit: BSAFs matched well with the measured BSAFs for all treatments (Fig. 2, Table S9). However, parameter estimates need to be interpreted and used carefully. To obtain this good fit, the ingestion rate (I) needed to be estimated for each treatment separately, though sediment and species do not differ between treatments. The bioaccumulation model provided satisfactorily narrow confidence intervals for the fitted parameters in all treatments (Table S9). Similar to BSAF values, the fitted ingestion rates decreased with increasing exposure concentration (T1 > T2 > T3, Table S9). The model shows that systems reached steady state at the end of experiment (Table S10). Sediment was the main uptake route (100\%) for L. hoffmeisteri across all treatments (Table S10).

\subsection{Effects of TCS on algae, benthic macroinvertebrates, and D. magna}

After 28 days, the phytoplankton chlorophyll-a concentrations, used to assess algal density, were low in controls and all treatments $(<0.25 \mu \mathrm{g} / \mathrm{L})$ and were significantly lower at higher treatment levels (T2, T3 and T4, 0.13-0.20 $\mu \mathrm{g} / \mathrm{L})$ compared to T1 and controls $(\sim 0.24 \mu \mathrm{g} / \mathrm{L})$ (Williams test, $p<0.05$ ) (Table S11, Fig. 3). Periphyton chlorophyll-a levels varied between 
treatments and systems. As with phytoplankton chlorophyll-a, periphyton chlorophyll-a was higher in controls and low TCS treatments than higher TCS treatments in both systems (Table S11, Fig. 3). In the microcosms containing the introduced organisms, periphyton chlorophylla concentration was significantly lower in $\mathrm{T} 2$, T3, and T4 $\left(0.27-0.4 \mu \mathrm{g} / \mathrm{dm}^{2}\right)$ than controls and T1 (0.64-0.65 $\left.\mu \mathrm{g} / \mathrm{dm}^{2}\right)$ (Williams test, $\left.p<0.05\right)$. In the microcosms without introduced organisms, periphyton chlorophyll-a concentration was significantly lower in T3 and T4 (0.37-0.4 $\left.\mu \mathrm{g} / \mathrm{dm}^{2}\right)$ compared to controls, T1, and T2 $\left(6.25-6.57 \mu \mathrm{g} / \mathrm{dm}^{2}\right)$ (Williams test, $p<$ 0.05). Between the two systems, periphyton chlorophyll-a levels were significantly higher in the controls, T1, and T2 in the system without introduced organisms $\left(6.25-6.57 \mu \mathrm{g} / \mathrm{dm}^{2}\right.$ compared to $\left.0.27-0.65 \mu \mathrm{g} / \mathrm{dm}^{2}\right)$; levels in T3 and T4 were similar in both systems $(\sim 0.4$ $\left.\mu \mathrm{g} / \mathrm{dm}^{2}\right)$.

Differences in survival of snails and worms were observed between treatments with higher TCS concentrations (T3 and T4) and controls, T1 and T2 (Williams test, $p<0.05$ ). A reduction in snail count $(16.67 \% \pm 0.3 \%)$ and worm count $(85.2 \% \pm 0.02 \%)$ was observed in T3 by the end of the experiment (Table 2). Complete mortality of snails and worms was observed in T4 after 28 days exposure (Table 2). There was no evidence of reproductive activity in either the snails or worms in any of controls or treatments during the study. Based on these observed effects, the 28-d survival NOEC values for snails and worms were determined to be $8 \mu \mathrm{g} / \mathrm{g}$ dw TCS. There was no significant difference in wet weight of the surviving snails or worms between controls and treatments at the end of the experiment (Kruskal-Wallis test).

There were no D. magna left in any of controls or treatments by the end of the exposure period, except for T3 where 2 ind./L were recorded. Additionally, no midge larvae or adults 
were found in any of the microcosms including controls at the end of the experiment. Although midge emergence was observed after day 2, it was difficult to record their emergence number and date, since the microcosms were open systems.

\section{Discussion}

We found a significant dissipation of TCS in the microcosms after 28 days exposure (3.43 $( \pm 0.56)-11.4( \pm 0.63) \%)$. This is in agreement with data reported from other studies of TCS degradation by microorganisms (e.g., Ying et al., 2007 (half-life of 18 days under aerobic conditions and little degradation within 70 days under anaerobic conditions); Huang et al., 2015 (half-lives of 55-239 days)). TCS accumulated in the worm with BSAFs in the range of 0.38-3.55: BSAF decreased with increasing concentration. Although the presence of introduced organisms increased TCS concentrations in the water phase compared to systems without introduced organisms, it did not significantly influence TCS dissipation in the microcosms. TCS at $8 \mu \mathrm{g} / \mathrm{g} \mathrm{dw}, 5$-fold higher than the currently detected maximum (1.33 $\mu \mathrm{g} / \mathrm{g} \mathrm{dw}$, Zhao et al., 2010), did not influence the survival and growth of snails and worms under the conditions in this study.

\subsection{Fate of TCS in the microcosms}

Deposition of suspended particles from the water phase to the sediment phase and the partitioning of TCS between water and sediment likely contributed to the TCS decrease in the water phase during the exposure period. This was confirmed by the measured turbidity values of larger than $100 \mathrm{NTU}$ at the start of exposure given the 3 days deposition of systems. Because the aqueous TCS concentration was significantly higher in the microcosms with introduced organisms than without, it suggests that worms via bioturbation flushed TCS from the sediment to the overlying water. The contribution of abiotic degradation (i.e., photolysis 
and hydrolysis) to the loss of TCS in the microcosms was negligible during the experiment period, therefore the dissipation of TCS observed in the microcosms can mainly be attributed to biotic degradation and bioaccumulation. However, the presence of the introduced organisms did not significantly increase the dissipation of TCS in microcosms in this study. Unlike this study, Dai et al (2012) examined the fate of a sediment-associated fragrance material, acetyl cedrene (AC), in sediments inhabited by the polychaete, Capitella teleta, and found that more than $88 \%$ of the AC disappeared during 14 days of exposure when C. teleta was present (both at medium and high densities) compared to only about $25-30 \%$ in the absence of this worm. This difference can be attributed to many factors including a difference in invertebrate density, species differences in e.g., biotransformation capacity and properties of chemicals (e.g., Log Kow).

The amount of TCS that accumulated in the worm tissue varied between treatments, with BSAFs in the range of $0.38-3.55$. This is likely related to differences in ingestion rate among treatments, as demonstrated by the bioaccumulation model: higher TCS levels in sediment lead to lower ingestion rates (Table S10). In a similar species of sediment dwelling worms (Lumbriculus variegatus), studies report both similar 28-day BSAF for TCS (1.4) as the current study (Dang et al., 2016), but also higher BSAF values (9.04) (Karlsson et al., 2016). For other species, BSAFs for TCS were lower. For example, in the freshwater clam, Corbicula fluminea, BSAF values of less than 1 have been reported (Edziyie et al. 2011). Such differences may be related to differences in sediment concentration that can impact the ingestion rate of organism (Pedersen et al., 2009), and sediment characteristics, such as organic matter content and pH value (Diepens et al., 2015; Karlsson et al., 2016), which would affect the retention of TCS in sediment and uptake of TCS into the worms. Likewise, differences in species traits (e.g., body size, diet preference and ingestion rate) can also be 
influencing factors (Diepens et al., 2015). Additionally, the possible biodegradation of TCS in the worms and/or by sediment microbial community could have lowered the tissue levels of TCS. For example, TCS is biodegraded into methyl-triclosan by nematodes, causing an increase in concentrations of methyl-triclosan but a lowering of TCS in the nematodes tissue (Macherius et al., 2014). However, the methyl-TCS is more persistent than TCS and is more prone to bioaccumulate in aquatic organisms, such as fish (James, et al., 2012; Pycke et al., 2014). Except for methylation, dihydroxylation is another degradation pathway occurring on the aromatic rings of TCS, which has been reported for microorganisms with 2,4-

dichlorophenol as the major intermediate (Kim et al., 2011; Lee et al., 2012). However, little (eco)toxicological information is known about these degradation products of TCS. Further work, therefore, will be needed to assess their risks on aquatic organisms.

\subsection{Effects of TCS on introduced organisms in the microcosms}

The effects of TCS differed amongst the organisms that were introduced to the microcosms. In these microcosms, both phytoplanktonic and periphytonic chlorophyll-a content decreased as the concentrations of TCS in the sediment increased. Algae are known to be particularly sensitive to TCS, with growth inhibition typically being recorded at $\mathrm{EC}_{50}$ values of $0.53 \mu \mathrm{g} / \mathrm{L}$ to $430 \mu \mathrm{g} / \mathrm{L}$ (Table S12), depending on the test conditions and species (e.g., Orvos et al., 2002; Yang et al., 2008). Algal growth was likely inhibited in higher TCS treatments due to elevated water concentrations of TCS and increased turbidity during the first week, both a result of sediment resuspension at the start of the experiment. Initial high turbidity (30-131 NTU) and grazing pressure from D. magna during the first week likely contributed to low chlorophyll-a contents in T1 and controls. In microcosms without introduced organisms, the periphyton chlorophyll-a levels were also reduced in the higher TCS concentration treatments, 
demonstrating that TCS was an important factor influencing the growth of periphyton given the similar turbidity values among treatments during the exposure period.

There were no D. magna in any controls or treatments at the end of exposure, except for T3. Given the lack of predators and good water quality in microcosms during the exposure period, shortage of food was probably the main cause of death, rather than TCS stress. However, because multiple measurements of survival were not taken during the experiment, the effects of TCS on D. magna cannot be accounted. NOEC for D. magna survival was determined at $200 \mu \mathrm{g} / \mathrm{L}$ (21-d TCS exposure, Orvos et al., 2002), and a $96 \mathrm{~h} \mathrm{LC}_{50}$ at $338 \mu \mathrm{g} / \mathrm{L}$ TCS (Wang et al., 2013). As these concentrations are in line with, or less than, some of the TCS concentrations used here, it is likely that TCS would have influenced $D$. magna survival in the highest TCS treatment. As all Chironomus sp. emerged during the experiment it is recommended to use first-instar larvae instead of fourth-instar larvae which we incorporated into the systems.

Here, the survival of snails and worms was reduced once TCS concentrations reached $80 \mu \mathrm{g} / \mathrm{g}$ $\mathrm{dw}$, with a complete loss of individuals at $240 \mu \mathrm{g} / \mathrm{g} \mathrm{dw}$ TCS. Based on these values, we determined the 28-d survival NOEC values for these organisms as $8 \mu \mathrm{g} / \mathrm{g}$ dw TCS. On the same species of worm as used here, the toxic effects of TCS have been observed to begin at much higher concentrations. For example, an $\mathrm{LC}_{50}$ value of $2046 \mu \mathrm{g} / \mathrm{L}$ has been reported for L. hoffmeisteri in a 96-h acute toxicity test (Wang et al., 2013), which is higher than the TCS initial level $(1190 \mu \mathrm{g} / \mathrm{L})$ in the overlying water of the highest TCS treatment used here. This may be related to the difference in $\mathrm{pH}$ between the two studies ( 8.0 in that study compared to below 7.5 in this study), which can affect the toxicity of TCS as TCS in neutral form is more toxic than in ionic form (Orvos et al., 2002; Roberts et al., 2014). Additionally, the presence 
of sediment in the microcosms used here increases the possible modes of TCS uptake by $L$. hoffmeisteri (pore water, sediment and overlying water), and also that TCS concentration in the overlying water could include TCS sorbed to colloids in the presence of sediment, which is not the case for water-only setups (as in Wang et al., 2013). Although we did not measure TCS effects on worm ingestion rate, the bioaccumulation model suggests that worm actively avoided ingesting TCS contaminated sediments at concentration of $8 \mu \mathrm{g} / \mathrm{g} \mathrm{dw}$, resulting in lower uptake of TCS from the ingested sediment. Similar results have been reported for adult gastropod Potamopyrgus antipodarum exposure to galaxolide (HHCB, a polycyclic musk), whose feeding rate declined with increasing HHCB concentration (Pedersen et al., 2009). In the future work, we therefore recommend to analyse the sediment ingestion rate for sedimentdwellers when assessing effects and bioaccumulation of hydrophobic chemicals.

\subsection{Implications for environmental risk assessment}

Although previous research has reported bioaccumulation of various organic contaminants in aquatic organisms, there are no data on the fate of sediment-associated TCS in microcosms consisting of water, sediment and a diverse community. TCS concentrations up to a few $\mu \mathrm{g} / \mathrm{g}$ dw have been monitored in subtropical freshwater surface sediments impacted by direct and indirect discharge of wastewater (Table S13). Our results suggest that sediment-associated TCS at such environmental concentrations is unlikely to impose a direct toxicological risk, at least in the short term, to snails and worms present in the water-sediment systems $(\mathrm{NOEC}=8$ $\mu \mathrm{g} / \mathrm{g}$ dw TCS). We also measured the bioaccumulation of TCS in the oligochaete worm, and the results suggest that sediment-associated TCS is available for uptake in L. hoffmeisteri and may be biotransformed. However, further studies are required to investigate whether there is metabolism of TCS in worms and their related ecotoxicity to aquatic organisms. 
In conclusion, this study showed that TCS accumulated in the worm used in this study. Although benthic invertebrates may have contributed to the mobilization of TCS from the sediment to the water phase, they did not make a significant contribution to the removal of TCS from the microcosms under the experimental conditions used here. Partitioning of TCS into sediment can decrease aquatic concentrations and reduce toxicity of TCS to pelagic species, but could pose an increased risk to benthic species. However, the results shown here indicate that current maximal measured environmental concentrations in the subtropics probably do not affect the survival and growth of snails and worms in contaminated sediments, at least in the short term. For environmental risk assessment, long term effects, indirect effects and bio-magnification of TCS in the food web should be further investigated.

\section{Acknowledgments}

The authors would like to acknowledge the financial support from the Research Institute for Fragrance Materials. We also thank the partial financial support from the National Natural Science Foundation of China (NSFC 41473105) and State Key Laboratory of Organic Geochemistry (SKLOG2016-A03). 


\section{References}

Ankley, G.T., Cook, P.M., Carlson, A.R., Call, D.J., Swenson, J.A., Corcoran, H.F., Hoke, R.A., 1992. Bioaccumulation of PCBs from sediments by oligochaetes and fishes: Comparison of laboratory and field studies. Can J Fish Aquat Sci 49, 2080-2085.

Banta, G.T., Andersen, O., 2003. Bioturbation and the fate of sediment pollutants: experimental case studies of selected infauna species. Vie et milieu 53, 233-248.

Bedoux, G., Roig, B., Thomas, O., Dupont, V., Le Bot, B., 2012. Occurrence and toxicity of antimicrobial triclosan and by-products in the environment. Environmental Science and Pollution Research 19, 1044-1065.

Brausch, J.M., Rand, G.M., 2011. A review of personal care products in the aquatic environment: environmental concentrations and toxicity. Chemosphere 82, 1518-1532.

Burton, J.A.G., 2002. Sediment quality criteria in use around the world. Limnology 3, 65-76.

Cantwell, M.G., Wilson, B.A., Zhu, J., Wallace, G.T., King, J.W., Olsen, C.R., Burgess, R.M., Smith, J.P., 2010. Temporal trends of triclosan contamination in dated sediment cores from four urbanized estuaries: evidence of preservation and accumulation. Chemosphere 78, 347-352.

Chen, F., Ying, G.-G., Yang, J.-F., Zhao, J.-L., Wang, L., 2010. Rapid resolution liquid chromatography-tandem mass spectrometry method for the determination of endocrine disrupting chemicals (EDCs), pharmaceuticals and personal care products (PPCPs) in wastewater irrigated soils. Journal of Environmental Science and Health Part B 45, 682693.

Chen, Z.-F., Ying, G.-G., Lai, H.-J., Chen, F., Su, H.-C., Liu, Y.-S., Peng, F.-Q., Zhao, J.-L., 2012. Determination of biocides in different environmental matrices by use of ultra-highperformance liquid chromatograph-tandem mass spectrometry. Analytical and Bioanalytical Chemistry 404, 3175-3188. 
Clesceri, A., Greenberg, A., 1998. Eaton. Standard methods for the examination of water and wastewater, 20th ed, American Public Health Association/American Water Works Association/Water Environment Federation, Washington DC.

Dai, L., Selck, H., Salvito, D., Forbes, V.E., 2012. Fate and effects of acetyl cedrene in sediments inhabited by different densities of the deposit feeder, Capitella teleta. Environmental Toxicology and Chemistry 31, 2639-2646.

Dang, V.D., Kroll, K.J., Supowit, S.D., Halden, R.U., Denslow, N.D., 2016. Bioaccumulation of legacy and emerging organochlorine contaminants in Lumbriculus variegatus. Archives of environmental contamination and toxicology 71, 60-69.

Diepens, N.J., Van den Heuvel-Greve, M.J., Koelmans, A.A., 2015. Modeling of bioaccumulation in marine benthic invertebrates using a multispecies experimental approach. Environmental Science \& Technology 49, 13575-13585.

Dussault, E.B., Balakrishnan, V.K., Sverko, E., Solomon, K.R., Sibley, P.K., 2008. Toxicity of human pharmaceuticals and personal care products to benthic invertebrates. Environmental Toxicology and Chemistry 27, 425-432.

ECHA (European Chemicals Agency). 2015. Biocidal Products Committee (BPC): Opinion on the Application for Approval of the Active Substance: Triclosan Product-type: 1. ECHA/BPC/066/2015. Helsinki, Finland. https://echa.europa.eu/documents/10162/efc985e4-8802-4ebb-8245-29708747a358 [accessed 10 July 2018].

Edziyie, R.E., 2011. Characterization of triclocarban, methyl-triclosan, and triclosan in water, sediment, and Corbicula fluminea (Muller, 1774) using laboratory, in situ, and field assessments. 
Eggleton, J., Thomas, K.V., 2004. A review of factors affecting the release and bioavailability of contaminants during sediment disturbance events. Environment international 30, $973-$ 980.

FDA (U.S. Food and Drug Administration). 2016. 21 CFR Part 310 Safety and Effectiveness of Consumer Antiseptics. Topical Antimicrobial Drug Products for Over-the-Counter Human Use. Final Rule. Fed Reg 81:61106-61130.Gorga, M., Insa, S., Petrovic, M., Barceló, D., 2015. Occurrence and spatial distribution of EDCs and related compounds in waters and sediments of Iberian rivers. Science of The Total Environment 503-504, 69-86.

Halden, R.U., Paull, D.H., 2005. Co-occurrence of triclocarban and triclosan in U.S. water resources. Environmental Science \& Technology 39, 1420-1426.

Hommen, U., Veith, D., Dülmer, U., 1994. A computer program to evaluate plankton data from freshwater field tests. Lewis publishers, Boca Raton, FL (USA). 503-513.

Huang, X., Wu, C., Hu, H., Yu, Y., Liu, J., 2015. Sorption and degradation of triclosan in sediments and its effect on microbes. Ecotoxicology and Environmental Safety 116, 7683.

James, M.O., Marth, C.J., Rowland-Faux, L., 2012. Slow O-demethylation of methyl triclosan to triclosan, which is rapidly glucuronidated and sulfonated in channel catfish liver and intestine. Aquatic toxicology 124, 72-82.

Josefsson, S., Leonardsson, K., Gunnarsson, J.S., Wiberg, K., 2010. Bioturbation-driven release of buried PCBs and PBDEs from different depths in contaminated sediments. Environmental science \& technology 44, 7456-7464.

Karlsson, M.V., Marshall, S., Gouin, T., Boxall, A.B.A., 2016. Routes of uptake of diclofenac, fluoxetine, and triclosan into sediment-dwelling worms. Environmental Toxicology and Chemistry 35, 836-842. 
Katz, D.R., Cantwell, M.G., Sullivan, J.C., Perron, M.M., Burgess, R.M., Ho, K.T., Charpentier, M.A., 2013. Factors regulating the accumulation and spatial distribution of the emerging contaminant triclosan in the sediments of an urbanized estuary: Greenwich Bay, Rhode Island, USA. Science of The Total Environment 443, 123-133.

Khatikarn, J., Satapornvanit, K., Price, O.R., Van den Brink, P.J., 2016. Effects of triclosan on aquatic invertebrates in tropics and the influence of $\mathrm{pH}$ on its toxicity on microalgae. Environmental Science and Pollution Research, 1-10.

Kim, Y.-M., Murugesan, K., Schmidt, S., Bokare, V., Jeon, J.-R., Kim, E.-J., Chang, Y.-S., 2011. Triclosan susceptibility and co-metabolism -A comparison for three aerobic pollutant-degrading bacteria. Bioresource Technology 102, 2206-2212.

Lee, D.G., Zhao, F., Rezenom, Y.H., Russell, D.H., Chu, K.-H., 2012. Biodegradation of triclosan by a wastewater microorganism. Water Research 46, 4226-4234.

Li, H.-S., Sun, Q., Zhao, S.-J., Zhang, W.-H., 2000. Principles and techniques of plant physiological biochemical experiment. Higher Education Press, Beijing (in Chinese).

Liu, J.-L., Wong, M.-H., 2013. Pharmaceuticals and personal care products (PPCPs): A review on environmental contamination in China. Environment international 59, 208224.

Macherius, A., Lapen, D.R., Reemtsma, T., Römbke, J., Topp, E., Coors, A., 2014. Triclocarban, triclosan and its transformation product methyl triclosan in native earthworm species four years after a commercial-scale biosolids application. Science of The Total Environment 472, 235-238.

Milbrink, G., 1973. On the use of indicator communities of Tubificidae and some Lumbriculidae in the assessment of water pollution in Swedish lakes. Zoon 1, 125-139. 
Orvos, D.R., Versteeg, D.J., Inauen, J., Capdevielle, M., Rothenstein, A., Cunningham, V., 2002. Aquatic toxicity of triclosan. Environmental toxicology and chemistry 21, 13381349.

Pedersen, S., Selck, H., Salvito, D., Forbes, V., 2009. Effects of the polycyclic musk HHCB on individual- and population-level endpoints in Potamopyrgus antipodarum. Ecotoxicology and Environmental Safety 72, 1190-1199.

Peng, F.-J., Pan, C.-G., Zhang, M., Zhang, N.-S., Windfeld, R., Salvito, D., Selck, H., Van den Brink, P.J., Ying, G.-G., 2017. Occurrence and ecological risk assessment of emerging organic chemicals in urban rivers: Guangzhou as a case study in China. Science of the Total Environment 589, 46-55.

Pycke, B.F.G., Roll, I.B., Brownawell, B.J., Kinney, C.A., Furlong, E.T., Kolpin, D.W., Halden, R.U., 2014. Transformation Products and Human Metabolites of Triclocarban and Triclosan in Sewage Sludge Across the United States. Environmental Science \& Technology 48, 7881-7890.

Reiss, R., Mackay, N., Habig, C., Griffin, J., 2002. An ecological risk assessment for triclosan in lotic systems following discharge from wastewater treatment plants in the United States. Environmental Toxicology and Chemistry 21, 2483-2492.

Rico, A., Dimitrov, M.R., Van Wijngaarden, R., Satapornvanit, K., Smidt, H., Van den Brink, P.J., 2014. Effects of the antibiotic enrofloxacin on the ecology of tropical eutrophic freshwater microcosms. Aquatic Toxicology 147, 92-104.

Rippka, R., Deruelles, J., Waterbury, J.B., Herdman, M., Stanier, R.Y. 1979. Generic assignments, strain histories and properties of pure cultures of cyanobacteria. Microbiology, 111(1), 1-61. 
Roberts, J., Price, O.R., Bettles, N., Rendal, C., van Egmond, R., 2014. Accounting for dissociation and photolysis: a review of the algal toxicity of triclosan. Environmental toxicology and chemistry 33, 2551-2559.

Rodriguez, P., Reynoldson, T.B., 2011. The pollution biology of aquatic oligochaetes. Springer Science \& Business Media.

SCCS (2010) Opinion on: Triclosan, antimicrobial resistance (SCCP/1251/09). In: 2010, Scientific Committee on Consumer Safty (ed) Adopted by the SCCP during the 7th plenary on 22 June 2010.

Schaffner, L.C., Dickhut, R.M., Mitra, S., Lay, P.W., Brouwer-Riel, C., 1997. Effects of physical chemistry and bioturbation by estuarine macrofauna on the transport of hydrophobic organic contaminants in the benthos. Environmental science \& technology $31,3120-3125$.

Selck, H., Forbes, V.E., 2004. The relative importance of water and diet for uptake and subcellular distribution of cadmium in the deposit-feeding polychaete, Capitella sp. I. Marine Environmental Research 57, 261-279.

Sidney, L.A., Diepens, N.J., Guo, X., Koelmans, A.A., 2016. Trait-based modelling of bioaccumulation by freshwater benthic invertebrates. Aquatic Toxicology 176, 88-96.

Tachet H, Richoux P, Bournaud M, Usseglio-Polatera P. Invertebrates de'au douce; systematique, biologie, ecologie. CNRS Editions, Paris, France. 2000.

Tamura, I., Kimura, K., Kameda, Y., Nakada, N., Yamamoto, H., 2013. Ecological risk assessment of urban creek sediments contaminated by untreated domestic wastewater: potential contribution of antimicrobials and a musk fragrance. Environmental technology $34,1567-1575$. 
Thibodeaux, L.J., Valsaraj, K.T., Reible, D.D., 2001. Bioturbation-driven transport of hydrophobic organic contaminants from bed sediment. Environmental engineering science $18,215-223$.

Usseglio-Polatera P, Thomas S, Beisel JN, Moreteau JC. Biological trait structure of macroinvertebrate benthic communities. Illustration de la valeur indicatrice des caracteristiques biologiques des macroinvertebres d'une communaute benthique a differentes echellesd'observation. Ann limnol 1999; 35:71-80.

Usseglio-Polatera P, Bournaud M, Richoux P, Tachet H. Biological and ecological traits of benthic freshwater macroinvertebrates: Relationships and definition of groups with similar traits. Freshw Biol 2000; 43:175-205.

Van den Brink, P.J., Hattink, J., Bransen, F., Van Donk, E., Brock, T.C.M., 2000. Impact of the fungicide carbendazim in freshwater microcosms. II. Zooplankton, primary producers and final conclusions. Aquatic Toxicology 48, 251-264.

Vivien, R., Wyler, S., Lafont, M., Pawlowski, J., 2015. Molecular barcoding of aquatic oligochaetes: implications for biomonitoring. PloS one 10, e0125485.

Wang, X.-N., Liu, Z.-T., Yan, Z.-G., Zhang, C., Wang, W.-L., Zhou, J.-L., Pei, S.-W., 2013. Development of aquatic life criteria for triclosan and comparison of the sensitivity between native and non-native species. Journal of Hazardous Materials 260, 1017-1022.

Williamss, D.A., 1972. The comparison of several dose levels with zero dose control. Biometrics 28, 519-531.

Wu, C., Spongberg, A.L., Witter, J.D., 2009. Adsorption and degradation of triclosan and triclocarban in soils and biosolids-amended Soils. Journal of Agricultural and Food Chemistry 57, 4900-4905.

Yang, L.H., Ying, G.G., Su, H.C., Stauber, J.L., Adams, M.S., Binet, M.T., 2008. Growth inhibiting effects of 12 antibacterial agents and their mixtures on the freshwater 
microalga pseudokirchneriella subcapitata. Environmental Toxicology and Chemistry 27, 1201-1208.

Yao, L., Zhao, J.-L., Liu, Y.-S., Yang, Y.-Y., Liu, W.-R., Ying, G.-G., 2016. Simultaneous determination of 24 personal care products in fish muscle and liver tissues using QuEChERS extraction coupled with ultra pressure liquid chromatography-tandem mass spectrometry and gas chromatography-mass spectrometer analyses. Analytical and Bioanalytical Chemistry 408, 8177-8193.

Ying, G.-G., Yu, X.-Y., Kookana, R.S., 2007. Biological degradation of triclocarban and triclosan in a soil under aerobic and anaerobic conditions and comparison with environmental fate modelling. Environmental Pollution 150, 300-305.

Zhang, L., Niu, J., Wang, Y., 2016. Full life-cycle toxicity assessment on triclosan using rotifer Brachionus calyciflorus. Ecotoxicology and Environmental Safety 127, 30-35.

Zhao, J.-L., Ying, G.-G., Liu, Y.-S., Chen, F., Yang, J.-F., Wang, L., 2010. Occurrence and risks of triclosan and triclocarban in the Pearl River system, South China: from source to the receiving environment. Journal of hazardous materials 179, 215-222.

Zhou, G.-J., Peng, F.-Q., Zhang, L.-J., Ying, G.-G., 2012. Biosorption of zinc and copper from aqueous solutions by two freshwater green microalgae Chlorella pyrenoidosa and Scenedesmus obliquus. Environmental Science and Pollution Research 19, 2918-2929. 


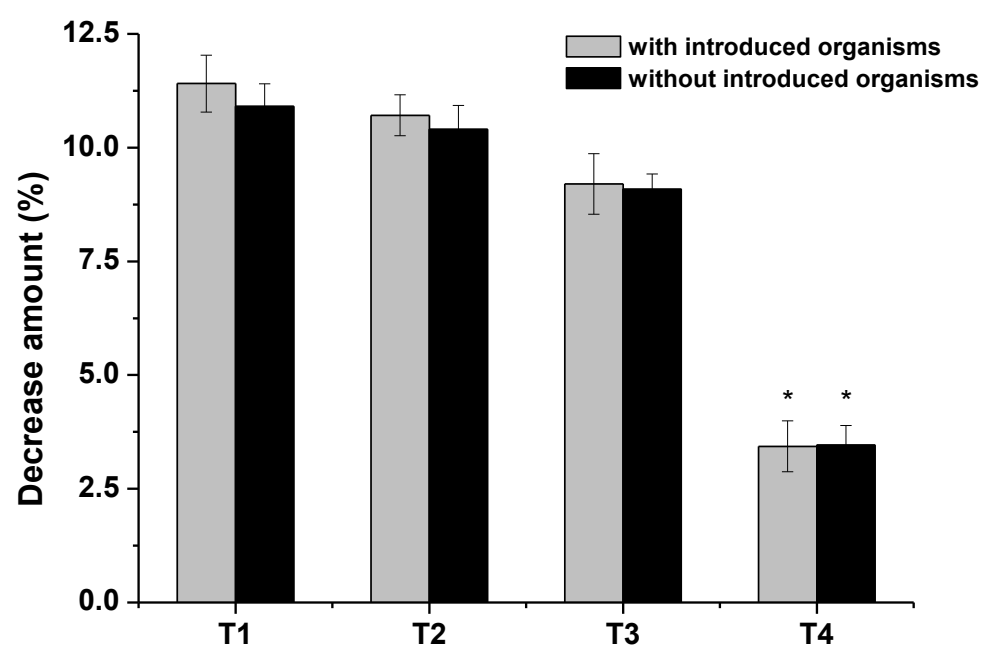

Fig.1. Changes of total TCS amount (\%) in the water/sediment systems at the end of exposure (day 28). Error bars represent standard error of the mean $(n=4) . T 1, T 2$, T3 and T4 represent treatments with spiked TCS concentrations of $0.8,8,80$ and $240 \mu \mathrm{g} / \mathrm{g}$ dry weight (dw), respectively. Grey and black bars represent treatment from microcosms with and without introduced organisms, respectively. 


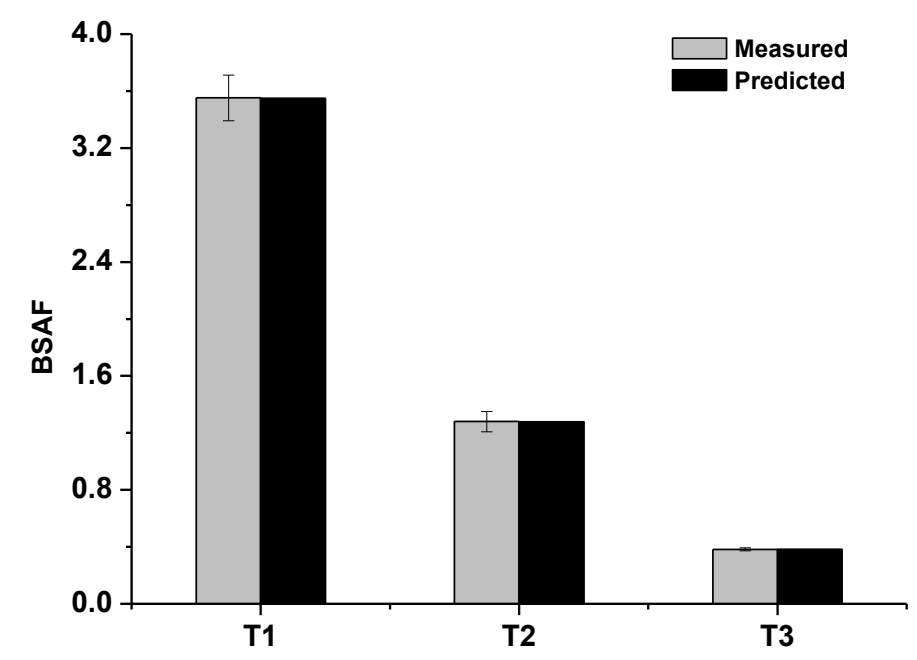

Fig. 2. Measured and predicted BSAF (Biota-Sediment-Accumulation-Factor) for each treatment in the $28 \mathrm{~d}$ bioaccumulation test with L. hoffmeisteri. Error bars represent standard error of the mean $(n=4)$. T1, T2 and T3 represent treatments with TCS concentrations of 0.8 , 8,80 and $240 \mu \mathrm{g} / \mathrm{g}$ dry weight $(\mathrm{dw})$, respectively. Grey and black bars represent measured and predicted BSAFs, respectively. 

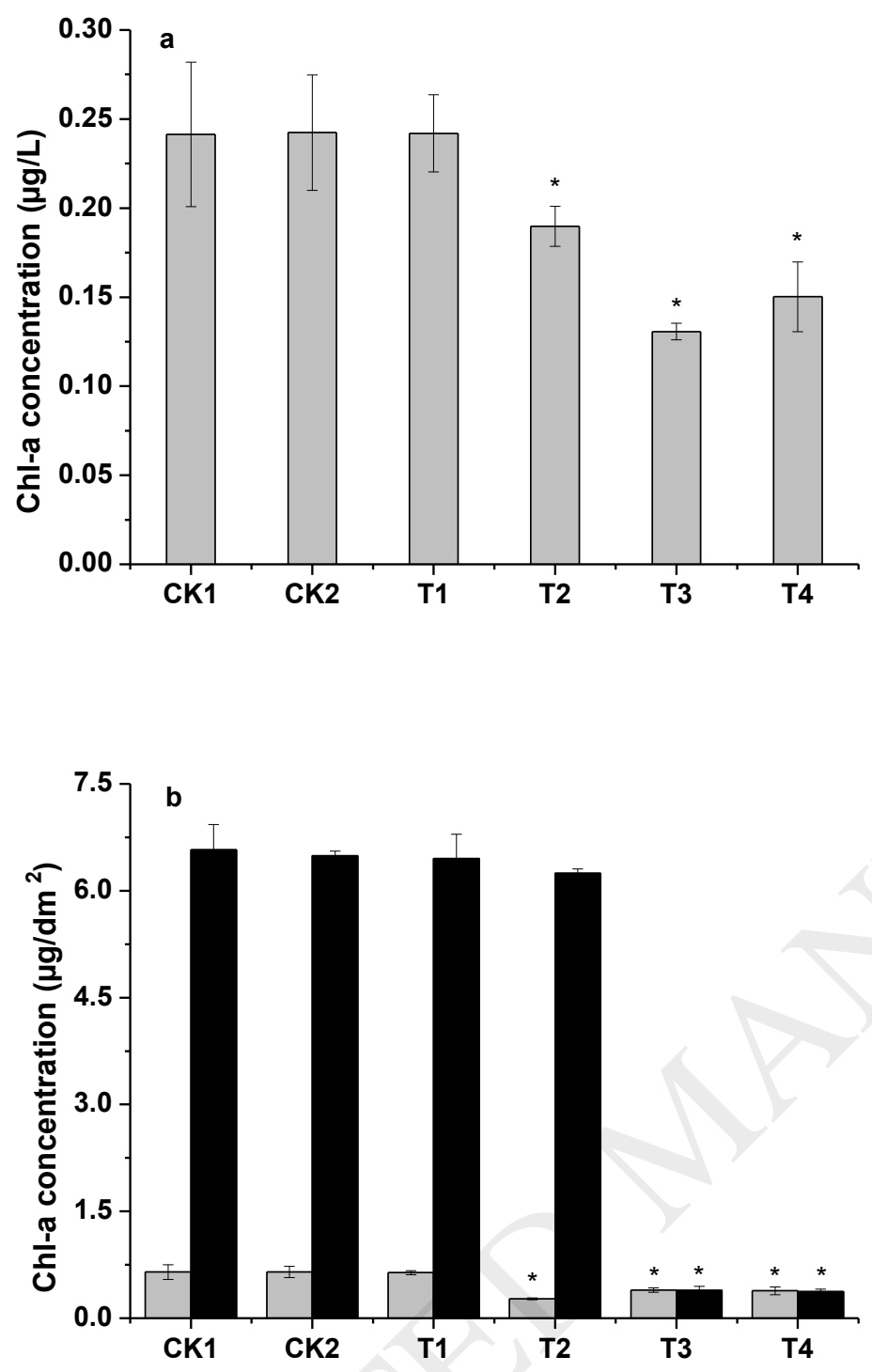

Fig.3. Chlorophyll a content in the water samples (a) and on the glass slides (b) at the end of exposure (day 28). Phytoplankton chl-a ( $\mu \mathrm{g} / \mathrm{L})$ (a) was analysed only in microcosms with introduced organisms, since no algae was introduced into the microcosms without introduced organisms. Error bars represent standard error of the mean $(n=4)$. CK1 and CK2 represent water control and acetone control, respectively. T1, T2, T3 and T4 represent treatments with TCS concentrations of $0.8,8,80$ and $240 \mu \mathrm{g} / \mathrm{g}$ dry weight $(\mathrm{dw})$, respectively. Grey and black bars represent treatment from microcosms with and without macroinvertebrates, respectively. 
Table 1 TCS concentration in overlying water, sediment and worm at the start and end of exposure.

\begin{tabular}{|c|c|c|c|c|c|c|c|c|c|}
\hline \multirow[b]{3}{*}{ Treatment } & \multirow{3}{*}{$\begin{array}{l}\text { Actual spiked } \\
\text { concentration } \\
(\mu \mathrm{g} / \mathrm{g} \mathrm{dw})\end{array}$} & \multicolumn{3}{|c|}{ Overlying water } & \multicolumn{3}{|l|}{ Sediment } & \multirow{2}{*}{\multicolumn{2}{|c|}{ Worm (day 28) }} \\
\hline & & \multirow[b]{2}{*}{$\begin{array}{l}\text { Day } 0 \\
(\mu \mathrm{g} / \mathrm{L})\end{array}$} & \multicolumn{2}{|l|}{ Day $28(\mu \mathrm{g} / \mathrm{L})$} & \multirow[b]{2}{*}{$\begin{array}{l}\text { Day 0 } \\
(\mu \mathrm{g} / \mathrm{g} \mathrm{dw})\end{array}$} & \multicolumn{2}{|l|}{ Day $28(\mu \mathrm{g} / \mathrm{g} \mathrm{dw})$} & & \\
\hline & & & $\begin{array}{l}\text { System with } \\
\text { introduced } \\
\text { organisms }\end{array}$ & $\begin{array}{l}\text { System without } \\
\text { introduced } \\
\text { organisms }\end{array}$ & & $\begin{array}{l}\text { System with } \\
\text { introduced organisms }\end{array}$ & $\begin{array}{l}\text { System without } \\
\text { introduced organisms }\end{array}$ & $\begin{array}{l}\text { Concentrations } \\
(\mu \mathrm{g} / \mathrm{g} l \mathrm{lw})\end{array}$ & BSAF \\
\hline CK1 & 0 & $<0.002$ & $<0.002$ & $<0.002$ & $<0.002$ & $<0.002$ & $<0.002$ & $<\mathrm{LOQ}$ & - \\
\hline CK2 & 0 & $<0.002$ & $<0.002$ & $<0.002$ & $<0.002$ & $<0.002$ & $<0.002$ & $<\mathrm{LOQ}$ & - \\
\hline $\mathrm{T} 1$ & 0.8 & $5.29 \pm 0.16$ & $0.395 \pm 0.022$ & $0.007 \pm 0.003$ & $0.762 \pm 0.00$ & $0.706 \pm 0.01$ & $0.713 \pm 0.00$ & $154 \pm 4.96$ & $3.55 \pm 0.16$ \\
\hline $\mathrm{T} 2$ & 8 & $39.6 \pm 1.51$ & $0.613 \pm 0.030$ & $0.013 \pm 0.007$ & $7.72 \pm 0.01$ & $7.11 \pm 0.05$ & $7.17 \pm 0.04$ & $552 \pm 12.3$ & $1.28 \pm 0.07$ \\
\hline $\mathrm{T} 3$ & 80 & $292 \pm 6.05$ & $0.554 \pm 0.053$ & $0.123 \pm 0.005$ & $77.9 \pm 0.12$ & $72.6 \pm 0.53$ & $72.7 \pm 0.27$ & $1650 \pm 63.8$ & $0.38 \pm 0.01$ \\
\hline $\mathrm{T} 4$ & 240 & $1190 \pm 14.3$ & $0.237 \pm 0.029$ & $0.216 \pm 0.017$ & $232 \pm 0.66$ & $232 \pm 1.34$ & $232 \pm 1.02$ & $*$ & $*$ \\
\hline
\end{tabular}

CK1 and CK2 represent water control and acetone control, respectively.

T1, $0.8 \mu \mathrm{g} / \mathrm{g} \mathrm{dw}$ treatment; T2, $8 \mu \mathrm{g} / \mathrm{g}$ dw treatment; T3, $80 \mu \mathrm{g} / \mathrm{g}$ dw treatment; $240 \mu \mathrm{g} / \mathrm{g} \mathrm{dw}$ treatment.

$\mathrm{dw}$, dry weight.

ww, wet weight.

$\mathrm{BSAF}=\left(\mathrm{C}_{\mathrm{org}, \mathrm{ww}} / f_{\text {lip, }} \mathrm{ww}\right) /\left(\mathrm{C}_{\text {sed,Dw }} / f_{\text {om, } \mathrm{DW}}\right)$.

LOQ means method limit of quantitation $(=8 \mathrm{ng} / \mathrm{g} \mathrm{lw})$.

* No worms were present in $\mathrm{T} 4$ at the end of the experiment. 
Table 2 Counts of organisms surviving at the end of exposure (day 28).

\begin{tabular}{lllll}
\hline Treatment & Snail & Daphnia & Worm & Midge \\
\hline CK1 & 6 & 0 & $233 \pm 7$ & 0 \\
CK2 & 6 & 0 & $234 \pm 6$ & 0 \\
T1 & 6 & 0 & $235 \pm 4$ & 0 \\
T2 & 6 & 0 & $232 \pm 7$ & 0 \\
T3 & $5^{*}$ & $23 \pm 3$ & $35 \pm 5^{*}$ & 0 \\
T4 & $0^{*}$ & 0 & $0^{*}$ & 0 \\
\hline
\end{tabular}

CK1 and CK2 represent water control and acetone control, respectively.

$\mathrm{T} 1, \mathrm{~T} 2, \mathrm{~T} 3$ and T4 represent treatments with TCS spiked concentrations of $0.8,8,80$ and $240 \mu \mathrm{g} / \mathrm{g}$ dry weight $(\mathrm{dw})$, respectively.

* represents treatment showed significant difference using Williams test $(p<0.05)$. These significances were relative to the controls. 